\title{
Pharmacological thromboprophylaxis IN ACUTELY ILL MEDICAL PATIENTS: SOME WORK ReMANS tO BE DONE
}

The importance of preventing venous thromoembolism (VTE) in patients undergoing surgery has been widely investigated in the last decade, with good quality clinical trials. The effectiveness of unfractioned heparin (UFH) and low molecular weight heparin $(\mathrm{LMWH})$ in the prevention of pulmonary embolism (PE), one of the leading causes of inhospital death, has been clearly demonstrated'. Indeed, medical patients have not received the same careful attention given to surgical patients despite evidence from clinical studies that 50 to $70 \%$ of symptomatic venous thromboembolic events related to hospitalization actually occur in the medical population, ${ }^{2,3}$, and the evidence from autopsy studies that 70 to $80 \%$ of all in-hospital deaths related to PE are detected in medical patients ${ }^{1,4-7}$. Recent practice audits carried out in Europe and in North America reported a low prescription rate of pharmacological thromboprophylaxis in the medical setting ${ }^{8-10}$, notwithstanding the publication in the last 6 to 7 years of convincing results from a well known meta-analysis" and from a few large randomized controlled trials ${ }^{12-15}$. All of these showed that in this population either UFH or LMWH are safe and effective in the prevention of VTE. Based on these results, international guidelines have recently begun to recommend the use of pharmacological prophylaxis in acutely ill medical patients, that is to say patients with congestive heart failure, acute respiratory failure, sepsis, cancer, or inflammatory bowel disease ${ }^{16}$.

An additional confirmation of a persistent underuse (and inadequate use) of pharmacological thromboprophylaxis in hospitalized medical patients comes from the study by Rocha and colleagues published in this issue of the Revista da Associação Médica Brasileira ${ }^{17}$. The authors conducted this crosssectional study aiming to evaluate the adequacy of VTE prophylaxis in medical patients in the Brazilian environment. This study was part of a wider "cultural" sensibilization on the problem of thromboprophylaxis in medical patients, and was conducted prior to implementation of the local recommendations. In the population examined, $97 \%$ of the patients had at least one risk factor for VTE, but only $54 \%$ received some form of prophylaxis. Adequate doses of pharmacological prophylaxis were administered to $63 \%$ of the patients. Prophylaxis was properly conducted in only $33 \%$ of the patients. There was no difference in the utilization rate between public and private hospitals. There was a preference for $L M W H$ in private hospitals, especially for patients over 40 years of age and Caucasian patients while UFH was used more often for patients with contraindications to heparin treatment.

Several reasons may explain why pharmacological thromboprophylaxis in acutely ill medical patients remains underused.
Concern about bleeding risk and lack of perception that VTE is a "real issue" are presumably the most important causes of underuse. Medical patients often have co-morbidities that further increase bleeding risk or may entail contraindications to pharmacological thromboprophylaxis. These include impaired renal function, previous or active bleeding, concomitant use of antiplatelet drugs, uncontrolled hypertension, or large cerebral ischemic infarctions. Indeed, the benefits of antithrombotic drugs in this high bleeding risk group must be carefully weighted against their potential detriment. However, when pharmacological prophylaxis is unfeasible, mechanical methods such as elastic stockings or intermittent pneumatic compression must be considered. Before deciding against administration of any form of thromboprophylaxis, physicians should be aware that when VTE occurs following hospitalization, the clinical outcome of medical patients is significantly worse than that of surgical patients, for both an increased risk of fatal PE and of fatal/major bleeding events ${ }^{18}$.

A number of critical issues still remain to be addressed. The optimal dosing regimens of LMWH in patients with chronic renal insufficiency have not been adequately evaluated, and the efficacy and safety of reduced dosages, as often suggested, remain unproven. Recommendations for thromboprophylaxis for hospitalized cancer patients are currently the same as for non-cancer patients. However, different types of cancer, different stages of disease, and the various concomitant chemotherapies make cancer patients a very heterogeneous population, probably with different thrombotic and bleeding risks. So far, no studies have been conducted in this specific setting and only approximately I $5 \%$ of patients enrolled in major clinical trials on the prevention of VTE in medical patients actually had cancer ${ }^{12,14,15}$.

In conclusion, VTE in medical patients is a completely preventable disease and is a major threat when it occurs. To reduce this risk, researchers, physicians and health-careproviders should focus their attention on improving individual VTE and bleeding risk stratification, awareness of the problem magnitude, implementation and dissemination of international guidelines, and availability of non-pharmacological prophylactic strategies.

Wider use of adequate prophylactic strategies, both pharmacological and non-pharmacological is warranted, particularly in patients with serious and acute medical conditions.

Matteo Galli, Alessandro Squizzato, Walter Ageno Department of Clinical Medicine, University of Insubria, Varese, Italy U.O. Medicina Interna 1, Ospedale di Circolo, viale Borri 57, 21100 VARESE, ItALY

Phone: +39-0332-278594; FAX: +39-0332-278229; E-MAIL: AGEWAL@YAHOO.com 
References

I. Sandler DA, Martin JF. Autopsy proven pulmonary embolism in hospital patients: are we detecting enough deep vein thrombosis? J R Soc Med. 1989;82:203-5

2. Bouthier J. The venous thrombotic risk in nonsurgical patients. Drugs. 1996;52(Suppl): I 6-29.

3. Goldhaber SZ, Dunn K, MacDougall RC. New onset of venous thromboembolism among hospitalized patients at Brigham and Women's Hospital is caused more often by prophylaxis failure than by withholding treatment. Chest. 2000; | | 8: | 680-4.

4. Goldhaber SZ, Savage DD, Garrison RJ, Castelli WP, Kannel WB, Ncnamara PM, et al. Risk factors for pulmonary embolism: the Framingham study. Am J Med. 1983;74:1023-8

5. Anderson FA, Wheeler HB, Goldberg RJ, et al. A population-based perspective of the hospital incidence and case-fatality rates of deep vein thrombosis and pulmonary embolism. The Worcester DVT study. Arch Intern Med. 1991; | 51:933-8.

6. Lindblad B, Sternby NH, Bergqvist D. Incidence of venous thromboembolism verified by necropsy over 30 years. Br Med J. 1991;302:709- I I.

7. Baglin TP, White K, Charles A. Fatal pulmonary embolism in hospitalised medical patients. I Clin Pathol. 1997:50:609- I0.

8. Ageno W, Squizzato A, Ambrosini F, Dentali M, Marchesi C, Mera V, et al. Thrombosis prophylaxis in medical patients: a retrospective review of clinical practice patterns. Haematologica. 2002;87:746-50

9. Anderson FA Jr, Tapson VF, Decousus H. IMPROVE, a multinationa observational cohort study of practices in prevention of venous thromboembolism in acutely ill medical patients: a comparison with clinical study patient populations. Blood. 2003; I 02: I | 46. [abstract].

10. Rahim SA, Panju A, Pai M, Ginsberg J. Venous thromboembolism prophylaxis in medical inpatients: a retrospective chart review. Thromb Res.
2003:| ||:2|5-9.

I I. Mismetti P, Laporte-Simitsidis S, Tardy B, Juillard-Delsart D, Decousus H. Prevention of venous thromboembolism in internal medicine with unfractionated or low molecular weight heparins: a meta-analysis of randomised clinical trials. Thromb Haemost. 2000;83: I 4-9.

12. Samama MM, Cohen AT, Darmon JY, Desjardins E, Eldor A, Janbon C, et al. A comparison of enoxaparin with placebo for the prevention of venous thromboembolism in acutely ill medical patients. N Engl J Med. 1999; 341:793-800.

13. Kleber FX, Witt C, Vogel G, Koppenhagen K, Schomaker U, Flasbach AV, et al. Randomized comparison of enoxaparin with unfractionated heparin for the prevention of venous thromboembolism in medical patients with heart failure or severe respiratory disease. Am Heart J. 2003; | 45:6 I 4-2 I.

14. Leizorovicz A, Cohen AT, Turpie AGG, Olsson CG, Vaitkus PT, Goldhaber SZ, et al. A randomized placebo controlled trial of dalteparin for the prevention of venous thromboembolism in 3706 acutely III medical patients: the PREVENT medical thromboprophylaxis study. Circulation. 2004; I 1 0:874-9.

I 5. Cohen AT, Davidson B, Gallus AS, Lassen MR, Prins MH, Tomkowski W, et al. Fondaparinux for the prevention of VTE in acutely ill medical patients. BMJ. 2006:332:325-9.

16. Geerts WH, Heit JA, Clagett P, Pineo GF, Colwell CW, Anderson FA Jr, et al. Prevention of venous thromboembolism. Chest. 200 I; I I 9: I 32S-75S.

17. Rocha ATC, Braga P, Ritt G, Lopes AA. Inadequação de tromboprofilaxia venosa em pacientes clinicos hospitalizados. Rev Assoc Med Bras. 2006;52(6).

18. Monreal M, Kakkar AK, Caprini JA, Barba R, Uresandi F, Valle R, et al. The outcome after treatment of venous thromboembolism is different in surgical and acutely ill medical patients. Findings from the RIETE Registry. J Thromb Haemost. 2004;2: | 892-8. 